và cộng sự (2011). FIGO classification system (PALM-COEIN) for causes of abnormal uterine bleeding in nongravid women of reproductive age. International Journal of Gynecology \& Obstetrics, 113 (1) 3-13.

5. K. H. Lee, J. K. Kim, M. A. Lee và cộng sự (2016). Relationship between uterine volume and discontinuation of treatment with levonorgestrelreleasing intrauterine devices in patients with adenomyosis. Archives of Gynecology and Obstetrics, 294 (3), 561-566.

6. J. Magalhães, J. M. Aldrighi và G. R. de Lima (2007). Uterine volume and menstrual patterns in users of the levonorgestrel-releasing intrauterine system with idiopathic menorrhagia or menorrhagia due to leiomyomas. Contraception,
75 (3), 193-198.

7. R. Varma, H. Soneja, K. Bhatia và cộng sứ (2008). The effectiveness of a levonorgestrelreleasing intrauterine system (LNG-IUS) in the treatment of endometrial hyperplasia-A long-term follow-up study. European Journal of Obstetrics \& Gynecology and Reproductive Biology, 139 (2), 169-175.

8. J. Struble, S. Reid và M. A. Bedaiwy (2016). Adenomyosis: A Clinical Review of a Challenging Gynecologic Condition. Journal of Minimally Invasive Gynecology, 23 (2), 164-185.

9. V. E. Radzinsky, M. B. Khamoshina, E. N. Nosenko và cộng sự (2016). Treatment strategies for pelvic pain associated with adenomyosis. Gynecological Endocrinology, 32 (sup2), 19-22.

\title{
ĐÁNH GIÁ KẾT QUẢ THAY LẠI KHỚP HÁNG NHÂN TẠO TẠI BỆNH VIỆN VIỆT ĐỨC TỪ NĂM 2015 ĐẾN 2018
}

\section{TÓM TẮT}

Thay khớp háng nhân tão phát triển tại nước ta khoảng trên 15 năm nay. Mỗi khớp háng nhân tạo có tuổi thọ nhất định nên khớp háng nhân tạo có thể bị hỏng. Việc chỉ đinh và đưa ra phương pháp thay lai khớp háng phải được nghiên cứu. Mục tiêu: Đánh giá kết quả thay lại khớp háng nhân tạo. Đối tượng và phương pháp: Nghiên cứu can thiệp lâm sàng 23 trường hợp hỏng khớp háng nhân tao được thay lai khớp háng từ năm 2015 đến 2018 tại Bệnh viện Việt Đức. Kết quả: Có 20 trường hợp hỏng khớp do lỏng ổ cối hoăcc lỏng chuôi khớp, hoặc mòn ổ cối; 3 trường hợp hỏng khớp do gãy dưới chuôi và gãy cổ chuối khớp được thay lại khớp háng. 9 khớp háng thay lại toàn phần, 6 khớp thay lại ố cối và 8 khớp thay lại chuôi khớp. Chức năng khớp háng cải thiên đáng kể với 17 trường hợp đạt kết quả tốt, 6 trường hợp đạt kết quả khá. Kết luận: Phát hiện sớm hiện tượng hỏng khớp háng, thay lai khớp háng phù hợp giúp cải thiện chức năng khớp háng cho bệnh nhân.

Tư khóa: thay lại khớp háng nuhân tạo.

\section{SUMMARY}

EVALUATE THE RESULTS OF REVISION HIP ARTHROPLASTY AT VIET DUC HOSPITAL FROM 2015 TO 2018

Hip arthroplasty has developed in our country for 15 years. Each artificial hip has longevity and is gradually defective so revision hip arthroplasty has to

\footnotetext{
${ }^{1}$ Bệnh viện Việt Đức

${ }^{2}$ Dai hoc Y Hà Nôi

Chịu trách nhiệm chính: Trân Mạnh Hùng

Email: drhung30@gmail.com

Ngày nhận bài: 7.5.2021

Ngày phản biện khoa học: 25.6.2021

Ngày duyệt bài: 6.7.2021
}

\section{Trần Mạnh Hùng ${ }^{1}$, Nguyễn Xuân Thuỳ ${ }^{2}$}

be studied. Objective: To evaluate the results of revision hip arthroplasty. Patients and methods: An interventional study included 23 cases who had damaged artificial hip underwent revision hip arthroplasty from 2015 to 2018 at Viet Duc Hospital. Results: 20 failure cases caused by loosen stem or acetabular implant, or worn acetabulum; 3 failure cases caused by femoral shaft fracture just below stem and the other had stem neck fracture. 9 cases had performed total hip replacement, 6 cases were replaced acetabular implant and 8 cases had to be replaced stem. Hip function improved significantly better in total: 17 good and 6 fair. Conclusions: Early detection defective artificial hip and revision hip replacement can help improve hip function.

Keyword: revision hip arthroplasty

\section{I. ĐăT VẤN ĐỀ}

Kỹ thuật thay khớp háng nhân tạo cho các khớp háng bị hỏng là một tiến bộ lớn về mặt kỹ thuật, giúp cải thiện tốt mức độ đau khớp, phục hồi tốt chức năng khớp háng, giúp người bệnh sinh hoạt bình thường. Sau khi thay khớp háng xuất hiện những thay đổi cấu trúc xương xung quanh khớp nhân tạo làm ảnh hưởng tới kết quả cũng như tuổi thọ khớp háng như hiện tượng lỏng chuôi, các ố tiêu xương quanh ổ cối hay chuôi khớp háng, hiện tượng mòn khớp hay do sai sót về kỹ thuât như lỏng khớp, khớp có tư thế không đúng dẫn tới trật khớp hay mỏi khớp, nhiễm trùng... [1] Mặt khác, mỗi loại khớp háng có một tuối thọ nhất định nên khớp háng nhân tạo không tồn tại vĩnh viễn. Do vậy cần phải phát hiện các dấu hiệu hỏng khớp háng để thay thế khớp háng kịp thời giúp cải thiện chức năng của khớp háng. Thay lai khớp háng là thay lại 
một phần hay toàn bộ khớp háng. Tùy vào mức độ tổn thương của các bộ phận mà quyết định thay một phần hay toàn thể khớp háng.

Tại Việt Nam thay khớp háng thường quy đã phát triển khoảng trên 15 năm nay. Thay lại khớp háng nhân tạo bắt đầu được thực hiện khoảng trên 5 năm nay với một vài báo cáo bước đầu [2]. Tuy vậy vẫn chưa có nghiên cứu nào sâu về thay lại khớp háng. Chính vì vậy chúng tôi tiến hành nghiên cứu này với mục tiều đánh giá kết quả thay lại khớp háng nhẩn tạo tại Bệnh viện Việt Đức từ 2015 đến 2018.

\section{II. ĐỐI TƯỢNG VÀ PHƯƠNG PHÁP NGHIÊN CỨU}

Nghiên cứu can thiệp lâm sàng trên 23 bệnh nhân hỏng khớp háng nhân tạo không do nhiễm trùng có chỉ định thay lại khớp háng nhân tạo từ 2015 đến 2018 tại Bệnh viện Việt Đức.

\section{Tiêu chuẩn lựa chọn bệnh nhân:}

- Đau khớp háng sau thay khớp háng, hoặc trật khớp háng nhiều lần.

- Hình ảnh Xquang: lỏng chuôi hay lỏng ổ cối khớp háng, mòn khớp, trật khớp, gãy chuôi khớp, gãy xương đùi sau thay khớp háng ... [3][4]

Tiêu chuẩn loại trừ: - Bệnh nhân bị nhiễm trùng khớp háng nhân tạo.

- Xét nghiệm bạch cầu máu tăng cao, máu lắng tăng.

- Bệnh nhân không đồng ý tham gia vào nghiên cứu.

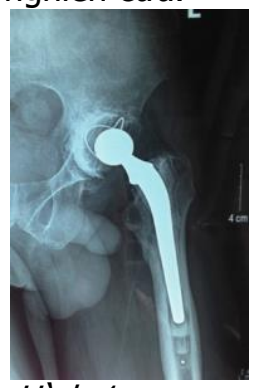

Hinh 1

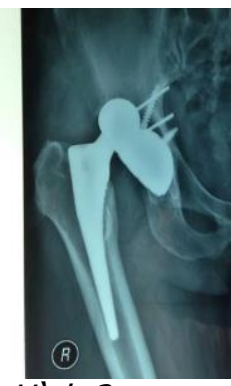

Hinh 2

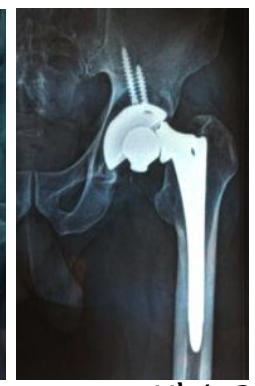

Hinh 3
Hinh 1: Lỏng chuôi và ố cối khớp háng

Hinh 2: Trật khớp háng nhân tạo

Hinh 3: Gãy cố chuôi khớp háng nhân tạo

Kỹ thuật thay lại khớp háng nhân tạo:

- Tư thể bệnh nhân: nằm nghiêng 90 độ về phía chân lành.

- Đường vào: rạch da theo đường mổ aũ (sau bên).

- Đánh giá mức độ hỏng khớp: lỏng chuôi hay ổ cối, tổn thương xương quanh khớp.

- Tùy tổn thương mà thay lại một phần hay toàn bộ khớp háng:

+ Kỹ thuật thay lại ổ cối: Tháo bỏ ổ cối, làm sạch xung quanh ổ cối, thay lại ổ cối có xi măng (có thể có dọ đi kèm nếu tổn thương ổ cối nặng), thay ổ cối không xi măng khi ổ cối còn tốt (kèm theo ghép xương đồng loại, hoặc xương tự thân).

+ Kỹ thuật thay lại chuôi: Tháo bỏ chuôi cũ (có thể phải mở cửa sổ xương), làm sạch ống tủy xương đùi, thay lại chuôi khớp háng bằng loại chuôi dài có xi hoặc không xi măng (có ghép xương đồng loại hoặc không).

- Lắp chỏm và đặt lại khớp háng.

- Đóng bao khớp, đặt dẫn lưu, đóng vết mổ.

Sau mổ, bệnh nhân được tập phục hồi chức năng. Đánh giá kết quả vị trí khớp háng bằng Xquang sau mổ 1-3 ngày. Chức năng khớp háng được đánh giá trước mổ và sau mổ 3 tháng theo Merle d'Aubigné - Postel [5].

\section{KẾT QUẢ NGHIÊN CỨU}

Nghiên cứu gồm 23 bệnh nhân bị hỏng khớp háng nhân tạo, trong đó có 16 bệnh nhân nam và 7 bệnh nhân nữ. Tuổi trung bình là 61,7 tuổi, bệnh nhân lớn tuổi nhất là 76 tuổi, thấp tuối nhất là 42 tuổi. Thời gian bệnh nhân sau bị đau lại sau thay khớp háng lần đầu trung bình là 5,4 năm. Bệnh nhân thay lại lâu nhất sau 13 năm, thay lại sớm nhất là 14 tháng do bị ngã gãy ngang chuôi.

Triệu chứng trước mổ:

- 20 bệnh nhân có triệu chứng đau quanh khớp, đau tăng khi vận động, giảm đi khi nghỉ ngơi; 3 bệnh nhân chấn thương gồm: 1 bệnh nhân gãy cổ chuôi, 1 bệnh nhân gãy dưới chuôi khớp háng, 1 bệnh nhân gãy mấu chuyển bé lan xuống thân xương.

- 23 bệnh nhân xét nghiệm trước mổ bạch cầu và máu lắng trong giới hạn bình thường.

- Hình ảnh XQ trước mổ cho thấy có 16 bệnh nhân thay khớp háng toàn phần, 7 bệnh nhân thay khớp háng bán phần. Trong số 16 bệnh nhân thay khớp háng toàn phần, có 8 bệnh nhân thay khớp háng có xi măng (2 bệnh nhân lỏng chuôi, 2 bệnh nhân lỏng ố cối, 4 bệnh nhân bị lỏng cả chuôi và ổ cối); và 8 bệnh nhân thay khớp không xi măng (1 bệnh nhân gãy cổ chuôi, 4 bệnh nhân lỏng chuôi, 3 bệnh nhân lỏng ố cối). 7 bệnh nhân thay khớp háng bán phần gồm 3 bệnh nhân bị mòn ổ cối, 2 bệnh nhân gãy duới chuồi, 2 bệnh nhân lỏng chuôi kèm mòn ổ cối.

Kỹ thuật thay lại khớp háng: 17 bệnh nhân được thay lại chuôi khớp háng gồm: 1 bệnh nhân thay chuôi ngắn, 9 bệnh nhân thay chuôi dài bằng chuôi có xi măng; 7 bệnh nhân thay chuôi khớp háng không xi măng. 15 ổ cối được thay lại gồm: 6 ổ cối không xi măng không kèm ghép xương, 6 ổ cối không xi măng kèm 
ghép xương, 3 ổ cối có xi măng.

Sau mố, tất cả bệnh nhân liền vết mổ trong 10 ngày đầu. Tập PHCN sau mổ: trong 23 bệnh nhân sau mổ đều được tập PHCN, 9 bệnh nhân được tập tỳ đè đi lại trong tuần đầu tiên sau mổ, 4 bệnh nhân tập thụ động trong tháng đâu, đặc biệt 1 bệnh nhẩn tập tỳ đè muộn sau 3 tháng.

\section{Kết quả điêu trị}

- X quang sau mổ: Trong số 23 bệnh nhân của nghiên cứu, có 9 bệnh nhân thay lại khớp háng nhân tạo toàn phần, 14 bệnh nhân được thay lại khớp háng nhân tạo bán phần. 15 ổ cối thay lại có 12 ổ cối không xi măng, 3 ổ cối có xi măng, Kết quả chụp Xquang sau mổ cho thấy 15 ổ cối thay lại đều được đặt đúng vị trí. Với 17 chuôi khớp được thay lại, khi chụp Xquang thây các chuôi khớp đều nằm trong ống tủy của xương đùi. Với 14 bệnh nhân thay chuôi dài, vị trí cuối chuôi cách vị trí mở cửa sổ xương 2-3 lần chu vi xương đùi.

- Kết quả chức năng khớp háng theo Merle d'Aubigné - Postel:

\begin{tabular}{|c|c|c|}
\hline Kết quả & Trước mố & Sau mố \\
\hline Tốt, rất tốt & 0 & 17 \\
\hline Khá & 0 & 6 \\
\hline Trung bình & 10 & 0 \\
\hline Xấu & 13 & 0 \\
\hline
\end{tabular}

\section{BÀN LUẬN}

Tất cả 23 bệnh nhân được thay lại khớp háng đều trên 40 tuổi. Đây là độ tuổi có thời gian sống còn dài, nên việc hỏng khớp háng nhân tạo phải thay lại là cần thiết nhằm cải thiện chất lượng của cuộc sống. Mặt khác, tuổi bệnh nhân hỏng khớp háng do bệnh lý ngày càng trẻ nên việc thay lại khớp háng là tất yếu.

Thời gian thay lại khớp háng của nhóm nghiên cứu trung bình 5,4 năm, cao nhất là 13 năm, thấp nhất là 1 năm, thời gian này thấp hơn nhiều so với thời gian của nhóm tác giả khác khoảng 10 năm. Điều này có thể giải thích do chỉ định thay khớp háng bán phần và toàn phần có xi măng với lứa tuổi 50-60 là sớm, vì lứa tuổi này nhu cầu hoạt động còn cao, chất lượng xương còn tốt nên thay khớp háng bán phần dễ làm mòn ổ cối, và xi măng làm hủy xương, đồng thời kỹ thuật xi măng chưa tốt làm thời gian tồn tại khớp háng giảm xuống.

Về chỉ định thay lại khớp háng: trong 23 trường hợp thay lại khớp có 20 bệnh nhân có triệu chứng đau, đau nhiều khi vận động, giảm khi nghỉ ngơi. Xét nghiệm máu lắng và bạch cầu trong giới hạn bình thường cùng với kết quả Xquang có lỏng chuôi hoặc lỏng ổ cối hoặc mòn ổ cối với khớp háng bán phần, phù hợp với tổn thương trong mổ là không nhiễm trùng, lỏng ổ cối hay chuôi khớp háng, hoặc mòn ổ cối. Điều này khẳng định chỉ định thay lại khớp háng là hợp lý, phù hợp. Tuy nhiên để phát hiện sớm lỏng khớp háng các hiện tương tiêu xương quanh khớp cần phối hợp chụp CT khớp háng để có thái độ xử trí sớm, kịp thời nhằm tăng tuổi thọ khớp háng và thay lại khớp đúng lúc.

Về kĩ thuật thay lại ổ cối, trong nghiên cứu của chúng tôi các bệnh nhân khuyết ổ cối ít hoặc chất lượng ổ cối tốt đều được thay thế bằng ổ cối không xi măng kèm theo ghép xương đồng loại chỗ khuyết xương để đảm bảo độ vững của ổ cối. Về kĩ thuật thay chuôi khớp: 17 chuôi khớp háng được thay có 11 trường hợp phải mở cửa sổ xương đùi do hai trường hợp gãy cổ chuôi và gãy dưới chuôi thì chuôi khớp háng còn gắn kết với xương đùi, mặt khác do chuôi khớp không vững làm chuôi khớp lệch trục với xương đùi nên khi làm ống tủy xương đùi bị thủng. Vì vậy theo chúng tôi, việc mở cửa sổ xương nên chủ động trong trường hơp chuôi và xi măng khó lấy giúp hạn chế tổn thương của xương đùi.

Mặt khác trong mổ chúng tôi dùng 16/17 trường hợp là chuôi dài, các chuôi vượt qua vị trí yếu nhất của chuôi khớp (vị trí cuối chuôi) 2-3 lần chu vi của xương đùi, giúp cho khớp háng mới có chuôi vững hơn, giúp bệnh nhân sớm tập đi lại.

Về chức năng khớp háng, tất cả 23 trường hợp đều có chức năng khớp háng trước mồ trung bình và xâu theo Postel, do bệnh nhân nước ta có chất lượng sống chưa cao và điều kiện kinh tế thấp nên chỉ khi không đi lại được mới điều trị. Tuy nhiên chức năng khớp háng sau mổ thay lại đã cải thiện rõ rệt sau 3 tháng với 17 bênh nhân đạt kết quả tốt và 6 bênh nhân đạt kết quả khá. Điều này khẳng định thay lại khớp háng là cần thiết giúp cải thiện chức năng sống của người bệnh. Tuy vậy 6 trường hợp khá nằm ở các bệnh nhân có mở cửa sổ xương đùi, do phẫu thuật tổn thương nhiều, phần mềm co rút nhiều trong mổ nên khả năng phục hồi của bệnh nhân chậm hơn.

\section{KẾT LUÂ̂N}

Phẫu thuật thay lại khớp háng nhân tạo giúp bệnh nhân cải thiện chức năng khớp háng và chất lượng cuộc sống. Phẫu thuật được chỉ định khi bệnh nhân bị đau sau thay khớp háng, gãy xương đưi hoặc vỡ ổ cối sau chấn thương, hoặc trật khớp háng nhiều lần kèm theo chụp Xquang thẩy hiện tượng lỏng chuôi khớp, lỏng ổ cối, mòn khớp háng, trật khớp, gãy chuôi khớp, võ chỏm. 


\section{TÀI LIÊU THAM KHẢO}

1. Đào Xuân Thành (2012) "Nghiên cứu kết quả thay khớp háng toàn phần không xi măng và thay đổi mật độ xương quanh khớp háng nhân tạo" Luận văn tiến sĩ y học.

2. Đoàn Việt Quân (2010) "Thay lại khớp háng nhân tạo bằng khớp háng có xi măng nhân 23 trường hợ". y hoc thức hành só $6 / 2013$.

3. Christopher M. Haydon, "Revision Total Hip Arthroplasty with Use of a Cemented Femoral
Component. Results at a Mean of Ten Years" ] Bone Joint Surg Am. 2004;86:1179-1185.

4. M. Røkkum, M. Brandt, "Polyethylene wear, osteolysis and acetabular loosening with an HAcoated hip prosthesis" ] Bone Joint Surg [Br] 1999;81-B:582-9.

5. Merle d'Aubigné R. (1970), "Cotation chiffrée de la fonction de la hanche". Rev Chir Ortho Reparatrice Appar Mot, 56 (5), pp 481-86.

\section{KHẢO SÁT CHẤT ƯợNG CUỘC SỐNG CỦA NGƯờI BỆNH XƠ GAN KHÁM VÀ ĐIỀU TRI TẠI BỆNH VIỆN ĐA KHOA XANH PÔN}

\section{TÓM TẮT}

Mục tiêu: Mô tả chất lượng cuộc sống của người bênh xơ gan tai bênh viên đa khoa Xanh Pôn năm 2020. Phương pháp nghiên cứu: mô tả cắt ngang có phân tích trên 80 người bênh xơ gan đến khám và điều trị tại phòng khám tiêu hóa và khoa nội 2 bệnh viên đa khoa Xanh Pôn trong tháng 5 năm 2020. Kết quả: nghiên cứu cho thấy người bệnh trên 60 tuổi chiếm tỷ lệ cao nhất $46.3 \%(37 / 80)$, nam giới chiếm ưu thế $65 \%(52 / 80)$, người bệnh về hưu và sống ở Hà Nôi lần lượt chiếm ưu thế lần lướt là $51,3 \%(41 / 80)$ và $83.8 \%(67 / 80)$. Đa số người bệnh có tiền sử về sư dung rươu và thuốc lá chiếm tỷ lệ lần lướt $57.5 \%$ và $52.5 \%$. Nguyên nhân gây xơ gan cho người bệnh chủ yếu do viêm Gan B 73.8\%(59/80). Điểm trung bình CLCS chung của người bệnh xơ gan thấp 4.71(SD $= \pm$ $0,69)$, với $\min 2,9$ và max 6 . Trong đó điểm CLCS trung bình của phần triệu chứng ở ổ bụng, đạt 4,29 ( $\mathrm{SD}= \pm 1,17)$, điểm CLCS trung bình của phần mệt mỏi đạt 4,26 (SD = $\pm 0,94)$, điểm CLCS trung bình của phần triệu chứng toàn thân đạt 4,51 (SD $= \pm$ $0,75)$, điểm CLCS trung bình của phần hoat động đạt $4,63$ ( $S D= \pm 0,98)$, điểm CLCS trung bình của phần chức năng cảm xúc đat $4,81(\mathrm{SD}= \pm 0,78)$, cuối cùng là điểm CLCS trung bình của phần lo lắng cao 5,49 $(S D= \pm 3,31)$. Kết luân: Bênh xơ gan ảnh hưởng đến CLCS của người bệnh đặc biệt tình trạng mệt mói của người bệnh bị ảnh hưởng nhiều nhất.

\section{SUMMARY \\ QUALITY OF LIFE AMONG PATIENTS WITH CIRRHOSIS AND FACTORS RELATED TO QUALYTY OF LIFE \\ Objective: Descriptive quality of life and factors} related to quality of life among patients with Cirrhosis at Saint Paul General Hospital in 2020.Research

*Trường Đại học kỹ thuật y tế Hải Dương Chiu trách nhiếm chính: Phạm Thị Thanh Phương Email: phuonghmtu@gmail.com Ngày nhận bài: 4.5.2021

Ngày phản biên khoa học: 24.6.2021

Ngày duyệt bài: 6.7.2021

\section{Phạm Thị Thanh Phương*, Nguyễn Thị Nga*}

method: A cross-sectional description with analysis on 80 patients with cirrhosis who came for examination and treatment at the gastroenterology clinic and internal medicine department at Saint Paul General Hospital in May 2020. Research result: The study showed that patients over 60 years old accounted for the highest proportion $46.3 \%$ (37/80), male dominated with $65 \%(52 / 80)$, the majority were retirees and lived in Hanoi, respectively, accounting for $51.3 \%(41 / 80)$ and $83.8 \%(67 / 80)$. The majority of patients had a history of alcohol and tobacco use, accounting for $57.5 \%$ and $52.5 \%$, respectively. Most of the patients with cirrhosis are caused by hepatitis B $73.8 \%(59 / 80)$. The average QOL score of patients with cirrhosis is low $4.71(\mathrm{SD}= \pm 0.69)(<5)$, with min 2.9 and max 6. In which, the average QOL score of the symptomatic part of the abdomen reached 4.29 $(\mathrm{SD}= \pm 1.17)$, the average QOL score of the fatigue section reached $4.26(\mathrm{SD}= \pm 0.94)$, the average QOL score of the fatigue section reached 4.26 (SD $= \pm$ 0.94). The mean QOL score of the systemic symptoms part reached $4.51(\mathrm{SD}= \pm 0.75)$, the mean QOL score of the activity part reached $4.63(\mathrm{SD}= \pm 0.98)$, the mean QOL score of the sensory function section exposure reached 4.81 ( $S D= \pm 0.78$ ). Finally, the mean QOL score of the anxiety section reached 5.49 $(\mathrm{SD}= \pm 3.31)$. Conclusion: Cirrhosis affects the patient's QOL, especially fatigue is the most effect.

\section{I. ĐĂT VẤN ĐỀ}

Trong năm 2017, xơ gan đã gây ra hơn 1,32 triệu ca tử vong. Trong đó 440.000 người chiếm $33.3 \%$ là nữ và 883.000 người chiếm $66,7 \%$ là nam trên toàn câu.Tử vong do xớ gan chiếm $2,4 \%$ trong tổng số tử vong trên toàn cầu năm 2017. Có 10,6 triệu các trường hợp bị xơ gan mất bù và 112 triệu trường hợp bị xơ gan còn bù trong năm 2017 [5]. Ở Việt Nam năm 2016 tỷ lệ tử vong do xơ gan ở nam chiếm tỷ lệ 44,5 / 100000 dân/năm và $8,6 / 100000$ dân/năm ở nữ. [6]

Xơ gan là giai đoạn cuối của các bệnh về gan mật mạn tính. Người bệnh xơ gan ảnh hưởng tiêu 